\title{
Comprehensive insights into the response of Alexandrium tamarense to algicidal component secreted by a marine bacterium
}

\section{Xueqian Lei ${ }^{1,2+}$, Dong $\mathrm{Li}^{1,3+}, \mathrm{Yi} \mathrm{Li}^{1}$, Zhangran Chen ${ }^{1}$, Yao Chen ${ }^{1}$, Guanjing Cai ${ }^{1}, \mathrm{Xujun}$ Yang ${ }^{1}$, Wei Zheng ${ }^{1,2}$ * and Tianling Zheng ${ }^{1,2}$ *}

1 State Key Laboratory of Marine Environmental Science and Key Laboratory of the Ministry of Education for Coastal and Wetland Ecosystems, School of Life Sciences, Xiamen University, Xiamen, China

2 ShenZhen Research Institute of Xiamen University, ShenZhen, China

${ }^{3}$ Fujian Center for Disease Control and Prevention, Fuzhou, China

\section{Edited by:}

Weiwen Zhang, Tianjin University, China

\section{Reviewed by:}

Jiangxin Wang, Arizona State University, USA

Yiguo Hong, South China Sea Institute of Oceanology - Chinese Academy of Sciences, China

\section{*Correspondence:}

Tianling Zheng and Wei Zheng, State

Key Laboratory of Marine

Environmental Science and Key

Laboratory of the Ministry of

Education for Coastal and Wetland

Ecosystems, School of Life Sciences,

Xiamen University, No. 422, Siming

South Road, Xiamen, 361005, China

e-mail:wshwzh@xmu.edu.cn;

jedi@xmu.edu.cn

${ }^{t}$ These authors have contributed equally to this work.
Harmful algal blooms occur throughout the world, threatening human health, and destroying marine ecosystems. Alexandrium tamarense is a globally distributed and notoriously toxic dinoflagellate that is responsible for most paralytic shellfish poisoning incidents. The culture supernatant of the marine algicidal bacterium BS02 showed potent algicidal effects on A. tamarense ATGD98-006. In this study, we investigated the effects of this supernatant on $A$. tamarense at physiological and biochemical levels to elucidate the mechanism involved in the inhibition of algal growth by the supernatant of the strain BS02. Reactive oxygen species (ROS) levels increased following exposure to the BS02 supernatant, indicating that the algal cells had suffered from oxidative damage. The levels of cellular pigments, including chlorophyll a and carotenoids, were significantly decreased, which indicated that the accumulation of ROS destroyed pigment synthesis. The decline of the maximum photochemical quantum yield $(\mathrm{Fv} / \mathrm{Fm})$ and relative electron transport rate (rETR) suggested that the photosynthesis systems of algal cells were attacked by the BS02 supernatant. To eliminate the ROS, the activities of antioxidant enzymes, including superoxide dismutase (SOD) and catalase (CAT), increased significantly within a short period of time. Real-time PCR revealed changes in the transcript abundances of two target photosynthesis-related genes ( $p s b A$ and $p s b D$ ) and two target respiration-related genes ( $c o b$ and cox). The transcription of the respiration-related genes was significantly inhibited by the treatments, which indicated that the respiratory system was disturbed. Our results demonstrate that the BS02 supernatant can affect the photosynthesis process and might block the PS II electron transport chain, leading to the production of excessive ROS. The increased ROS can further destroy membrane integrity and pigments, ultimately inducing algal cell death.

Keywords: Alexandrium tamarense, algicidal bacterium, photosynthetic responses, oxidative stress, antioxidant enzyme, gene expression inhibition

\section{INTRODUCTION}

Phytoplankton play an important role in marine ecosystems as it is the major primary producer in the euphotic layer (Thyssen et al., 2014). However, some of them cause harmful algal blooms (HABs), which are usually associated with severe damage to aquatic ecosystems, have been occurring more frequently worldwide (Anderson, 1997b; Siswanto et al., 2013). As a result, impacts on the environment, tourism, fisheries, and public health due to HABs, which disturb the balance of the marine ecosystem, have all increased over the past few decades (Anderson et al., 2012). Alexandrium tamarense, an important algal bloom-causing organism, is responsible for most incidents of paralytic shellfish poisoning in addition to damaging the aquatic environment and human health (Franks and Anderson, 1992; Anderson, 1997a).

To control HABs, both physical (Sengco and Anderson, 2004; Tang et al., 2011) and chemical approaches (Sun et al., 2004; Kim et al., 2012) have been carried out. However, such approaches are costly and have not succeeded in completely resolving the problems associated with HABs, and they have also been shown to have negative effects on the aquatic environment due to secondary pollution (Lee et al., 2001; Ni etal., 2012; Zheng et al., 2013). Therefore, biological control agents, including bacteria (Bai etal., 2011; Zhang etal., 2014), viruses (Cai et al., 2011; Sheik et al., 2013), macrophytes (Jin and Dong, 2003) and protozoa (Jeong et al., 2008), have gained increasing attention. In recent years, bacteria have been considered to play a crucial role in the dramatic termination of blooms in coastal seawaters (Paul and Pohnert, 2013). Most of the known algicidal bacteria have been assigned to the genera Cellulophaga, Saprospira, Pseudoalteromonas, Alteromonas, Flavobacterium, Zobellia, Bacillus, Micrococcus, Planomicrobium, Pseudomonas, and Vibrio (Mayali and Azam, 2004; Kim et al., 2009). These algicidal bacteria either 
directly or indirectly attack algal cells, the former requiring cellto-cell contact (Mayali and Azam, 2004; Chen et al., 2014) and the latter producing substances with inhibitory effects on algal growth (Pokrzywinski et al., 2012).

Most reported algicidal bacteria have inhibitory effects on algal growth arising from the excretion of extracellular substances in a process termed allelopathy (Suikkanen et al., 2004). There are four aspects to be considered in relation to the potential pathways of the allelochemical inhibition of algal growth: the destruction of cell structures, alterations in enzymatic activities, and influences on algal photosynthesis or respiration (Peñuelas etal., 1996; Hong etal., 2009; Churro et al., 2010; Yang et al., 2011, 2013). During bloom succession, algal cells are subjected to diverse environmental stress conditions that lead to the production of reactive oxygen species (ROS), such as allelopathic interactions (Vardi et al., 2002), viral infection (Evans etal., 2006), UV exposure (Rijstenbil, 2002), $\mathrm{CO}_{2}$ availability (Vardi etal., 2007), and iron limitation (Thamatrakoln etal., 2012; Rosenwasser etal., 2014). Allelochemicals inhibit the photosynthetic efficiency and capacity of algal cells, causing them to produce numerous ROS (Apel and Hirt, 2004). To eliminate ROS and avoid oxidative damage, algal cells increase antioxidant defenses via the enzymatic and non-enzymatic antioxidants (Gill and Tuteja, 2010; Hamilton etal., 2012). In the enzymatic pathways, superoxide dismutase (SOD) and catalase (CAT) are important scavengers of ROS (Hong et al., 2009). However, when the production rate of ROS exceeds the scavenging rate, oxidative damage will occur, and many molecular sites will be attacked by the superfluous ROS (Avery, 2011).

Photosynthesis relies on the absorption of sunlight by chlorophyll molecules in photosystems I and II (PS I and II; Erickson etal., 1986). The $p s b \mathrm{~A}$ and $p s b \mathrm{D}$ genes encode two core proteins, D1 and D2 of PS II (Marder etal., 1987). cob is a cytochrome $b$-related gene in the mitochondria, and $c o x$ is a cytochrome oxidase synthetic gene (Tobe et al., 2010). Previous studies have indicated that alterations occur in photosynthesisand respiration-related gene expression in algae under allelochemical stress (Qian etal., 2010; Yang etal., 2013). However, few studies have focused on the damage caused by bacteria in relation to changes in photosynthesis- and respiration-related gene expression in A. tamarense.

To better understand the mechanism of the BS02 supernatantmediated inhibition of the growth of $A$. tamarense, we assessed the effect of this supernatant at the physiological and biochemical levels by measuring ROS, the responses of antioxidant enzymes (SOD and CAT) to oxidative stress, and the transcript abundance of photosynthesis ( $p s b \mathrm{~A}$ and $p s b \mathrm{D}$ )- and respiration ( $c o b$ and $c o x$ )related genes.

\section{MATERIALS AND METHODS BACTERIAL AND ALGAL CULTURES}

Vibrio sp. BS02 (GenBank No. HM596341.1) was isolated from a mangrove area in Zhangjiangkou, Fujian Province, China, and deposited into the Marin Culture Collection of China (MCCC) under accession number MCCC 1F01214. BS02 was cultured in marine agar $2216 \mathrm{E}$ broth $(5 \mathrm{~g}$ peptone, $1 \mathrm{~g}$ yeast extraction, and
$0.1 \mathrm{~g}$ ferric phosphorous acid, $\mathrm{pH}$ 7.4-7.8, brought to a total volume of $1 \mathrm{~L}$ using natural sea water), followed by incubation for $48 \mathrm{~h}$ at $28^{\circ} \mathrm{C}$.

Cultures of the experimental alga, A. tamarense ATGD98-006, were supplied by the Algal Culture Collection, Institute of Hydrobiology, Jinan University, Guangzhou, China. The cultures were cultivated in $\mathrm{f} / 2$ medium prepared with natural seawater (Guillard, 1975) under a 12:12 h light-dark cycle with a light intensity of $50 \mu \mathrm{mol}$ photons $\mathrm{m}^{-2} \mathrm{~s}^{-1}$ at $20 \pm 1^{\circ} \mathrm{C}$.

\section{ANALYSIS OF ALGICIDAL MODE AND ACTIVITY}

Strain BS02 was inoculated in $50 \mathrm{~mL} 2216 \mathrm{E}$ broth and grown to stationary phase at $28^{\circ} \mathrm{C}$ on a shaker at $150 \mathrm{rpm}$ for $48 \mathrm{~h}$. Then the cells were removed by centrifugation at $10,000 \times g$ for $10 \mathrm{~min}$, and the supernatant was filtered through a $0.22 \mu \mathrm{m}$ Millipore membrane. To assess whether the bacterial cells were completely removed from the filtrate, $150 \mu \mathrm{L}$ aliquots of filtrate were spread onto marine agar 2216E plates followed by incubation for 3 days at $28^{\circ} \mathrm{C}$. The remaining pellets were washed twice with sterile $\mathrm{f} / 2$ medium, and then the same volume of sterile $f / 2$ medium was added to resuspend the cells.

Flasks $(500 \mathrm{~mL})$ were prepared, with each containing $100 \mathrm{~mL}$ of sterile $\mathrm{f} / 2$ algal culture medium. BS02 cell-free supernatant, washed bacterial cells and a bacterial culture prepared as described above were added to the axenic exponentially growing algal cultures at a proportion of $1.5 \%(\mathrm{v} / \mathrm{v})$ in triplicate. Autoclaved $2216 \mathrm{E}$ broth served as a control. The algicidal rate was calculated according to the following formula (Li et al., 2014a):

$$
\text { Algicidal activiy }(\%)=(\mathrm{Nc}-\mathrm{Nt}) / \mathrm{Nc} * 100
$$

where $\mathrm{N}_{\mathrm{C}}$ represents the number of algal cells in the control group, and $\mathrm{N}_{\mathrm{t}}$ represents the number of algal cells in the treatment group.

Flasks $(500 \mathrm{~mL})$ were prepared, with each containing $100 \mathrm{~mL}$ of sterile $\mathrm{f} / 2$ algal culture medium. BS02 cell-free supernatant was added to the axenic exponentially growing algal cultures at proportions of $0.5(\mathrm{v} / \mathrm{v}), 1.0(\mathrm{v} / \mathrm{v})$, and $1.5 \%(\mathrm{v} / \mathrm{v})$ in triplicate. Autoclaved $2216 \mathrm{E}$ broth served as a control.

\section{SAMPLE PREPARATION AND SCANNING ELECTRON MICROSCOPY}

The BS02 supernatant prepared as described above was added to axenic exponentially growing algal cultures at a concentration of $1.5 \%(\mathrm{v} / \mathrm{v})$. Ten-milliliter aliquots of the culture medium were withdrawn based on algal cell vitality during the first day and then once every $12 \mathrm{~h}$. The samples were fixed in $0.1 \mathrm{M}$ sodium phosphate buffer (PBS, $8 \mathrm{~g} \mathrm{NaCl}, 0.2 \mathrm{~g} \mathrm{KCl}, 1.44 \mathrm{~g} \mathrm{Na}_{2} \mathrm{HPO}_{4}, 0.24 \mathrm{~g}$ $\mathrm{KH}_{2} \mathrm{PO}_{4}$, and $1 \mathrm{~L}$ distilled water; $50 \mathrm{mM}, \mathrm{pH}$ 7.4) containing $2.5 \%$ glutaraldehyde $(\mathrm{v} / \mathrm{v})$ for $2 \mathrm{~h}$ and then gently rinsed three times with PBS buffer followed by post-fixation in $1 \% \mathrm{OsO}_{4}$ in the same buffer for $2 \mathrm{~h}$. Next, the samples were gently rinsed three times with PBS buffer and dehydrated in a graded ethanol series (30, $50,70,90,95$, and $100 \%$ ), and they were finally stored in pure tertiary butanol at $4^{\circ} \mathrm{C}$ overnight. The samples were subsequently critical-point-dried and mounted on stubs. The preparation was sputter coated with gold-palladium at 60:40 and $25-30 \mathrm{~nm}$. The lysis process was visualized and imaged using scanning electron microscope (JSM-6390, JEOL). 
SAMPLE PREPARATION AND TRANSMISSION ELECTRON MICROSCOPY Algal cells were treated with the BS02 supernatant at a proportion of $1.5 \%(\mathrm{v} / \mathrm{v})$ for $48 \mathrm{~h}$. Samples were collected by centrifugation at $2000 \times g$ for $15 \mathrm{~min}$ and then fixed overnight at $4^{\circ} \mathrm{C}$ in $0.1 \mathrm{M}$ PBS buffer containing $2.5 \%$ glutaraldehyde (v/v). The fixed cells were rinsed three times in PBS buffer and post-fixed for $2 \mathrm{~h}$ in $1 \% \mathrm{OsO}_{4}$ in the same buffer. After being washed three times, the samples were dehydrated in a graded ethanol series and then embedded in araldite resin. Sections (60-80 nm) obtained with an ultramicrotome were stained in $3 \%$ acetic acid uranium-citric acid and viewed using a JEM2100HC transmission electron microscope (JEOL Ltd., Tokyo, Japan).

\section{DETERMINATION OF ROS LEVELS}

Intracellular ROS were detected following the protocol reported by Yin etal. (2005), with some modifications. The algal cells were incubated with $2^{\prime}, 7^{\prime}$ - dichlorofluorescin diacetate at $37^{\circ} \mathrm{C}$ in the dark for $1 \mathrm{~h}$ at a final concentration of $10 \mu \mathrm{M}$ and mixed every 5 min during this time. Then, following three washes with sterile $\mathrm{f} / 2$ medium, the cells were resuspended in $1 \mathrm{~mL}$ of this medium. Fluorescence intensity was monitored at an excitation wavelength of $488 \mathrm{~nm}$ and an emission wavelength of $525 \mathrm{~nm}$ using a spectrofluorometer.

\section{LIPID PEROXIDATION AND ANTIOXIDATIVE ENZYME ASSAYS OF A. tamarense}

Algal cells were collected by centrifugation at $5000 \times g$ for $5 \mathrm{~min}$, and the pellets were washed twice with sterile seawater. The cells were then resuspended in $1 \mathrm{~mL}$ PBS solution $(50 \mathrm{mM}$, $\mathrm{pH}$ 7.4), and cell disruption was conducted using an Ultrasonic Cell Disruption System (NingBo Scientiz Biotechnological Co., Ltd., China; $80 \mathrm{~W}$, ultrasonic time of $5 \mathrm{~s}$ and rest time of $5 \mathrm{~s}$ for 40 cycles) at temperatures of below $4^{\circ} \mathrm{C}$. Cell debris was removed by centrifugation at $10,000 \times g$ for $10 \mathrm{~min}$ at $4^{\circ} \mathrm{C}$. The supernatant was used to analyze the level of malondialdehyde (MDA) and the activities of SOD and CAT. All analysis methods were preformed according to the manufacturers' instructions at the Nanjing Jiancheng Bioengineering Institute, China (Zhang et al., 2011).

\section{PIGMENTS AND CHLOROPHYLL FLUORESCENCE MEASUREMENTS}

The chloroplast pigment contents were measured based on previously described methods (Inskeep and Bloom, 1985) with slight modifications. Ten milliliters of algal culture was collected by centrifugation at $5000 \times g$ for $10 \mathrm{~min}$ and washed with PBS $(50 \mathrm{mM}$, $\mathrm{pH}$ 7.4). Then, the pellets were resuspended in $90 \%$ ethanol overnight at $4^{\circ} \mathrm{C}$ to extract the chloroplast pigments. After complete extraction, the pellets were removed by centrifugation at $4^{\circ} \mathrm{C}$ for $10 \mathrm{~min}$ at $8000 \times g$, and the supernatant was used to measure absorbance at wavelengths of 665,645 , and $470 \mathrm{~nm}$. The pigments were calculated as follows:

$$
\text { Chlorophyll a }(\mathrm{mg} / \mathrm{L})=12.7 * \mathrm{~A}_{665}-2.69 * \mathrm{~A}_{645}
$$

Carotinoid $(\mathrm{mg} / \mathrm{L})=\left(1000 * \mathrm{~A}_{470}-2.05 * \mathrm{C}_{\text {Chlorophyll a }}\right) / 245$ where $\mathrm{A}_{665}, \mathrm{~A}_{645}$, and $\mathrm{A}_{470}$ represent absorbance values at wavelengths of 665,645 , and $470 \mathrm{~nm}$, respectively, and $\mathrm{C}_{\text {Chlorophyll a }}$ indicates the content of chlorophyll $a(\mathrm{Chl} a)$.

Pulse-amplitude modulation fluorescence measurements were obtained using a PAM-CONTROL Fluorometer (Walz, Effeltrich, Germany). The maximum photochemical quantum yield (Fv/Fm) were determined under an actinic light of $3000 \mu \mathrm{mol}$ photons $\mathrm{m}^{-2} \mathrm{~s}^{-1}$ based on previously described methods (Drábková et al., 2007) after the algal cells were dark-adapted for $15 \mathrm{~min}$. The relative electron transport rate $\left(\mathrm{rETR} / \mu \mathrm{mol}\right.$ electrons $\left.\mathrm{m}^{-2} \mathrm{~s}^{-1}\right)$ were measured followed (Kaplan et al., 2013), eight consecutive light levels of 156, 226, 337, 533, 781, 1077, 1593, and $2130 \mu \mathrm{mol}$ photons $\mathrm{m}^{-2} \mathrm{~s}^{-1}$ were applied at $15 \mathrm{~s}$ intervals.

\section{RNA EXTRACTION AND QUANTITATIVE REAL-TIME PCR ANALYSIS}

Fifty milliliters of algal culture was treated with the BS02 supernatant for $4 \mathrm{~h}$ and $24 \mathrm{~h}$ and then collected at $3000 \times \mathrm{g}$ for $5 \mathrm{~min}$ at $4^{\circ} \mathrm{C}$, and the pellets were quickly frozen in liquid nitrogen. Total RNA was extracted as quickly as possible using an RNAiso Kit (TaKaRa Company, China) following the manufacturer's instructions. Reverse transcription of the RNA was performed using a PrimeScript ${ }^{\text {TM }}$ RT-PCR Kit (TaKaRa Company, China). Two important photosynthesis genes ( $p s b \mathrm{~A}$ and $p s b \mathrm{D}$ ) and two target respiration-related genes ( $c o b$ and $c o x$ ) were selected for real-time qPCR analysis. Real-time PCR was carried out using SYBR ${ }^{\circledR}$ Premix EX Taq ${ }^{\text {TM }}$ II (TaKaRa Company, China). The $18 \mathrm{~S}$ rRNA gene was used as a reference gene to standardize the results. All of the primer pairs are listed in Table 1. The RT-PCR program was as follows: denaturation at $95^{\circ} \mathrm{C}$ for $20 \mathrm{~s}$ and 45 cycles of $95^{\circ} \mathrm{C}$ for $10 \mathrm{~s}$ followed by $60^{\circ} \mathrm{C}$ for $20 \mathrm{~s}$ and $72^{\circ} \mathrm{C}$ for $20 \mathrm{~s}$. The relative gene expression among the treatment groups was quantified using the $2^{-\Delta \Delta \mathrm{Ct}}$ method (Livak and Schmittgen, 2001).

\section{RESULTS}

\section{ALGICIDAL MODE AND ACTIVITY OF BS02 SUPERNATANT}

The algicidal activities were 88.9 and $89.6 \%$ after $60 \mathrm{~h}$ of treatment with the BS02 cell-free supernatant and bacterial cultures (Figure 1). We found that the cell-free supernatant showed high

Table 1 | Sequences of primer pairs used with Alexandrium tamarense for real-time PCR.

\begin{tabular}{ll}
\hline Gene name & Sequence $\left(\mathbf{5}^{\prime} \mathbf{-} \mathbf{3}^{\prime} \mathbf{)}\right.$ \\
\hline 18S rRNA & F:5'-GAATTCCTAGATATCGCAGTTCATC-3' \\
& R:5'-GCTAATCCACAATCTCGACTCCTC-3' \\
psbA & F: 5'-CAATGACAGTACGCCACCAA-3' \\
& R: 5'-CGAGATCAGCCTAGCTATTT-3' \\
psbD & F: 5'-TCTGTTACTTTACTTGATGACTGG-3' \\
& R: 5'-AGACAATGAAATGAACTACTGACC-3' \\
cob & F:5'-AGCATTTATGGGTTATGTNTTACCTTT-3' \\
& R:5'-AGCTTCTANDGMATTATCTGGATG-3 \\
cox & F: 5'-GAGGTGGAACAGGATGGA-3' \\
& R: 5'-GTGTAACAATGGCGGATT-3'
\end{tabular}




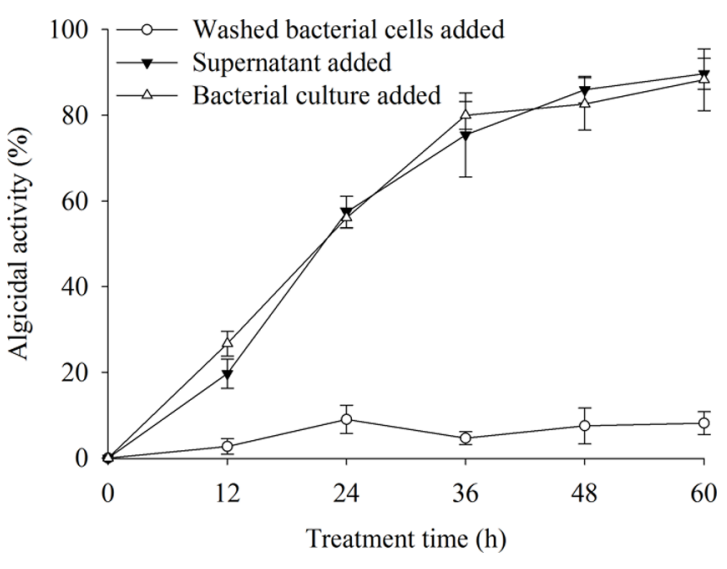

FIGURE 1 | The algicidal activity of different parts of bacterial cultures. All error bars indicate SE of the three replicates.

algicidal activity, which was similar to that of the bacterial cultures, whereas the washed bacterial cells did not show any obvious algicidal activity.

To determine the effective algal-lytic concentration of BS02 against $A$. tamarense, different proportions of the BS02 supernatant $(0.5,1.0$, and $1.5 \%)$ were inoculated in algal cultures. The proportion of $0.5 \%$ supernatant showed lower algal-lytic activity compared with the other two groups. The algicidal activities were $26.3,63.2$, and $89.5 \%$ after $60 \mathrm{~h}$ of treatment with the BS02 supernatant at the $0.5,1.0$, and $1.5 \%$ concentrations (Figure 2).

\section{EFFECTS OF BS02 SUPERNATANT ON MORPHOLOGICAL AND SUBCELLULAR STRUCTURES}

Based on the SEM observations and optical observations of samples from several time points, the algicidal process was inferred. Figure 3 shows the morphological changes of the A. tamarense cells, which were treated with the BS02 supernatant at a concentration of $1.5 \%$. Figure $3 \mathrm{~A}$ shows the normal cells in the control, which exhibited integrity of the cell wall and cell membrane, a visible fissure in the middle of the cell wall, and a quasi-spherical shape. Compared with these normal cells, the treated cells showed many differences in morphological characteristics and even structural damage (Figures 3B-F). The cells gradually became wrinkled, and one side of the cell wall began to appear sunken after $12 \mathrm{~h}$ of treatment (Figure 3B). After $24 \mathrm{~h}$ of treatment, the cells gradually shrank and the cytoplasm showed marked separation (Figure 3C). With increased exposure time, disintegration of the cell wall could be observed, the A. tamarense cells lysed, and part of the cellular substances were decomposed and released from the cell (Figures 3D,E). After $60 \mathrm{~h}$ of treatment, the A. tamarense cells were completely lysed and the cellular substances were completely decomposed and released (Figure 3F).

Transmission electron microscopy analysis showed apparent alterations in the ultrastructure of $A$. tamarense due to the effects of the BS02 supernatant. As shown in Figure 4, the structure and morphology of the algal cells were altered, and obvious plasmolysis and vacuolization could be observed following exposure to

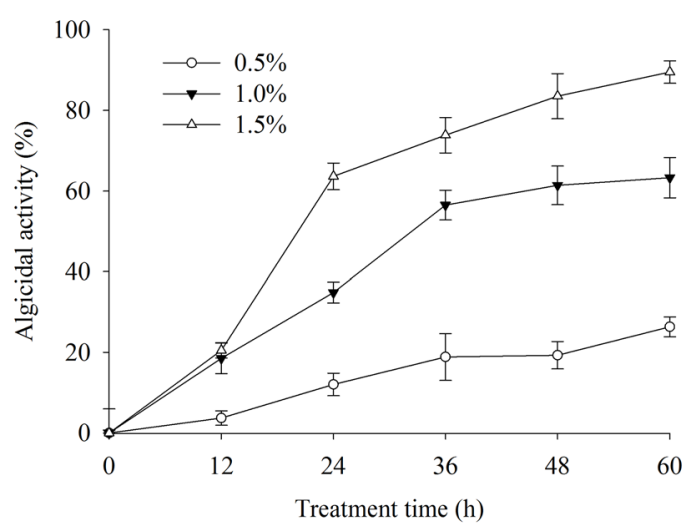

FIGURE 2 | Effect of different volume of BS02 supernatant on Alexandrium tamarense. All error bars indicate SE of the three replicates.

the BS02 supernatant (Figure 4B). In the control group, both the chloroplasts and mitochondria were intact and possessed double membranes (Figures 4C,E). Obvious modifications appeared in the chloroplasts and mitochondria of the treated algal cells; for example, the chloroplasts became sparse and their membrane structures were severely damaged (Figure 4D). In addition, the cristae of the mitochondria were distorted and their membranes were partially disintegrated (Figure $4 \mathbf{F}$ ).

\section{EFFECTS OF REACTIVE OXYGEN SPECIES AND MDA LEVELS}

To investigate whether exposure to different supernatant concentrations of BS02 damages algal cells, ROS levels and membrane lipid peroxidation were measured. ROS and lipid peroxidation levels, which are two important parameters, indicated the oxidative damage of the cellular components. Figure $\mathbf{5 A}$ shows the fluorescence intensity of ROS after $2 \mathrm{~h}$ of treatment with the supernatant. The ROS level was significantly $(p<0.01)$ increased in the treatment group compared with the control group. Intracellular ROS levels after $2 \mathrm{~h}$ of treatment with concentrations of $0.5,1.0$, and $1.5 \%$ of the supernatant were $1.58(p<0.01)$, $2.51(p<0.01)$, and 2.53 times $(p<0.01)$ those of the control, respectively.

Malondialdehyde can reflect the degree of lipid peroxidation, and it is used for evaluating the degree of cell damage. Figure 5B shows the MDA levels. After $12 \mathrm{~h}$ of treatment, the MDA level increased significantly $(p<0.05)$ compared to the control (Figure 5B). As the treatment time was prolonged, the MDA level was higher than that of the control group at each concentration. The MDA levels after treatment with the $1.5 \%$ concentration for $12,24,36$, and $48 \mathrm{~h}$ were $1.21(p<0.05), 1.60(p<0.01), 1.45$ $(p<0.01)$, and 1.99 times $(p<0.01)$ those of the control, respectively. Within $48 \mathrm{~h}$ of treatment, these levels were approximately $1.27(p<0.05), 1.35(p<0.01)$, and 1.99 times $(p<0.01)$ those of the control after exposure to the $0.5,1.0$, and $1.5 \%$ concentrations of the supernatant, respectively.

\section{EFFECTS OF ANTIOXIDATIVE ENZYME ACTIVITIES}

Cellular enzymatic activities, including those of SOD and CAT, were measured to investigate the cellular defense response induced 

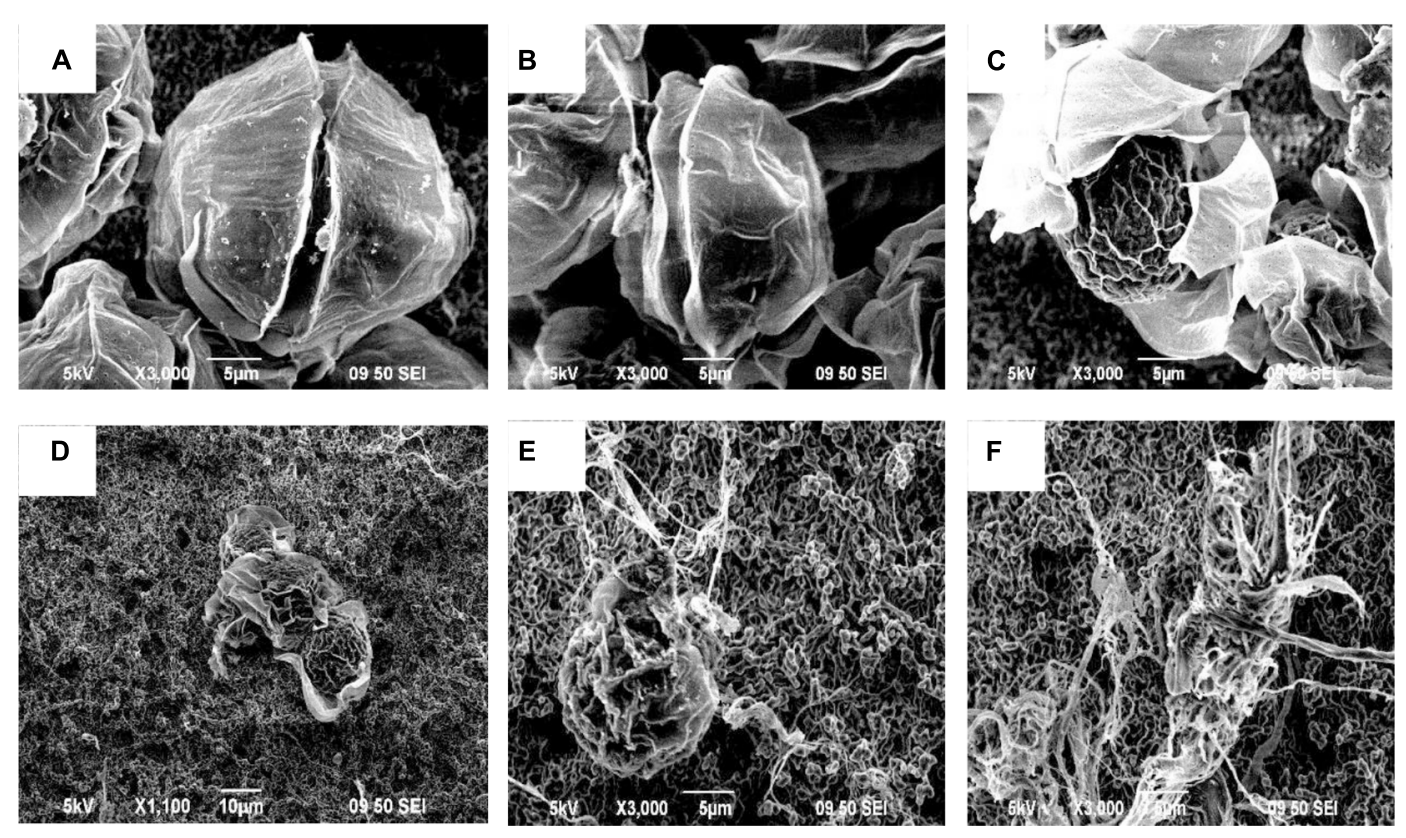

FIGURE 3 | Morphological changes of $A$. tamarense cells treated with BS02 supernatant at a concentration of $1.5 \%$ under a scanning electron microscope. Bars, (A-C,E,F) $5 \mu \mathrm{m}$; (D) $10 \mu \mathrm{m}$.

by the BS02 supernatant. Figure 6A shows that SOD activity increased significantly $(p<0.05)$ compared with the control after the algal cells were treated for $12 \mathrm{~h}$. The activity values were 1.39 $(p<0.05), 1.75(p<0.01)$ and 1.97 times $(p<0.01)$ those of the control when the algal cells were treated with $0.5,1.0$, and $1.5 \%$ of the BS02 supernatant, respectively. SOD activity increased gradually as the treatment time was prolonged, increasing to maximum levels after $36 \mathrm{~h}$ of treatment to values of $1.58(p<0.01), 3.45$ $(p<0.01)$, and 3.74 times $(p<0.01)$ those of the control after exposure to the supernatant at concentrations of $0.5,1.0$, and $1.5 \%$, respectively. However, SOD activity decreased significantly after the $36 \mathrm{~h}$ treatment at the 1.0 and $1.5 \%$ concentrations, showing that longer exposure times did not induce a significant increase in the activity of this enzyme.

Figure 6B shows that CAT activity increased significantly $(p<0.01)$ at the 1.0 and $1.5 \%$ concentrations compared with the control during the first $12 \mathrm{~h}$ of exposure, and its activity continued to increase to a maximal level over $24 \mathrm{~h}$. However, as the treatment time was prolonged, CAT activity decreased, although it was still obviously higher compared with the control, which is similar to the results for SOD. Although CAT activity decreased following treatment with the 1.0 and $1.5 \%$ concentrations as the exposure time was prolonged, it was also significantly $(p<0.01)$ higher compared with the control. The CAT activity values were $2.21(p<0.01), 7.22(p<0.01)$, and 9.31 times $(p<0.01)$ those of the control after exposure to the $0.5,1.0$, and $1.5 \%$ concentrations of supernatant for $24 \mathrm{~h}$, respectively.

\section{PIGMENT CONTENTS AND PHOTOSYNTHESIS EFFICIENCY ANALYSIS}

In the process of algal growth, the cellular pigments (Chl $a$ and carotenoid) in the algal cells were destroyed due to the effects of the supernatant at concentrations of 1.0 and $1.5 \%$ (Figure 7) compared with the control and $0.5 \%$ concentration. At $96 \mathrm{~h}$ of exposure, its inhibitory effects reached the highest level, and the levels of Chl $a$ were $\sim 35.3$ and $13.5 \%$ of those of the control after exposure to the supernatant at concentrations of 1.0 and $1.5 \%$, respectively (Figure 7A). However, the Chl $a$ level showed no obvious change at the $0.5 \%$ concentration compared with the control.

Figure 7B indicates that the carotenoid concentration increased significantly compared with the control within $24 \mathrm{~h}$ of exposure and decreased after $24 \mathrm{~h}$ of exposure at the 0.5 and $1.0 \%$ supernatant concentrations. Following $48 \mathrm{~h}$ of treatment, the carotenoid level was significantly $(p<0.01)$ decreased due to the effects of the supernatant at concentrations of 1.0 and $1.5 \%$, and its levels were approximately 75.7 and $43.8 \%$ of the control after exposure to the 1.0 and $1.5 \%$ concentrations, respectively. After $96 \mathrm{~h}$ of exposure, the carotenoid levels were significantly $(p<0.01)$ decreased at the supernatant concentration of $1.5 \%$, and its levels were found to be $88.6,77.3$, and $20.4 \%$ of the control level after exposure to the $0.5,1.0$, and $1.5 \%$ concentrations of supernatant, respectively.

To investigate the photosynthetic status of the algal cells under the stress caused by the BS02 supernatant, we calculated the $\mathrm{Fv} / \mathrm{Fm}$ and the rETR values, which, respectively, represented the photosynthetic efficiency and capacity of the cells. Within $1 \mathrm{~h}$ of treatment, the treatment group values were slightly lower than those of the control. The $\mathrm{Fv} / \mathrm{Fm}$ values showed significant decreases $(p<0.01)$ after $12 \mathrm{~h}$ of exposure to the BS02 supernatant (Figure 8A), and after $48 \mathrm{~h}$ of exposure, the values were approximately $65.6,52.8$, and $13.8 \%$ of those of the control after exposure to the supernatant at concentrations of 


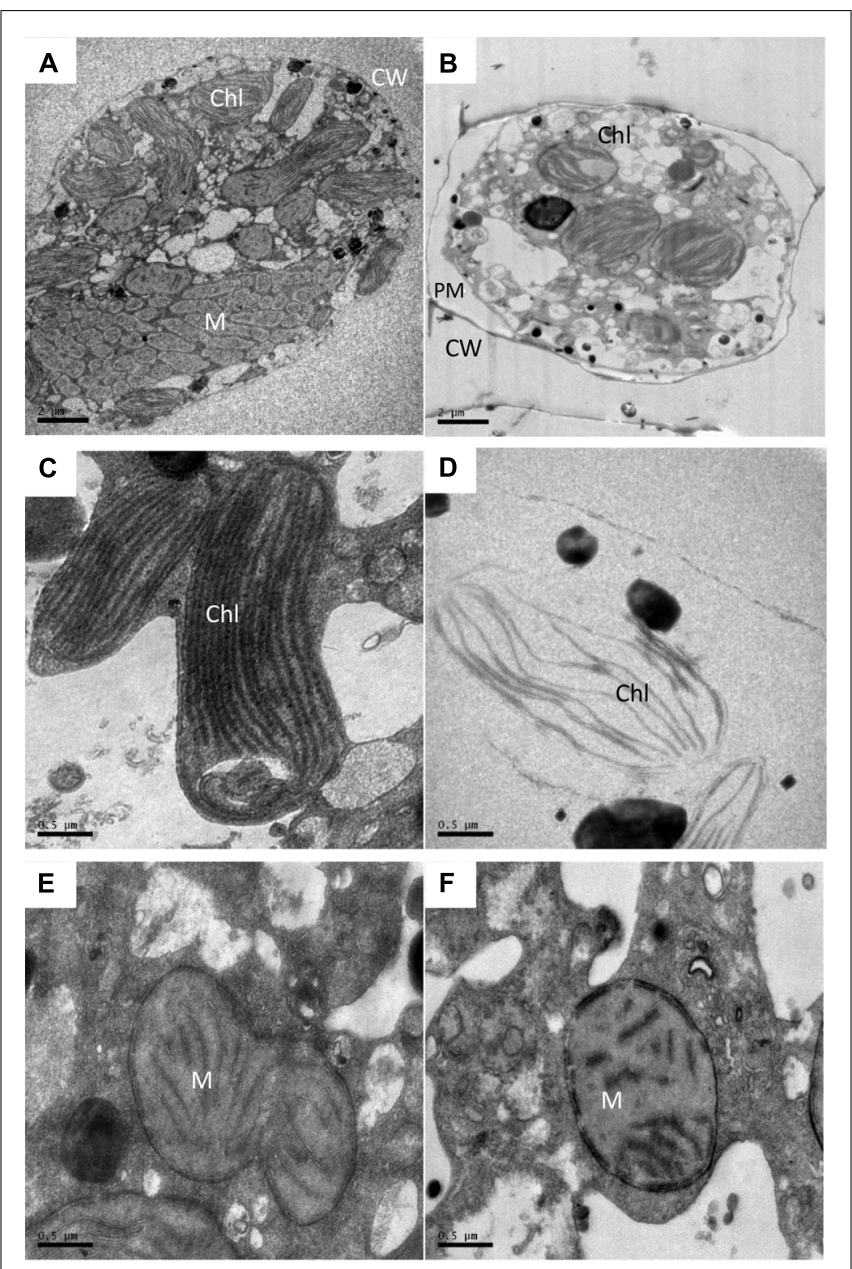

FIGURE 4 | Ultrastructure of $\boldsymbol{A}$. tamarense after exposure to $\mathrm{BS} 02$ supernatant with a concentration of $\mathbf{1 . 5 \%}$ for $\mathbf{4 8} \mathrm{h}$. (A,C,E): Control cell; (B,D,F): treatment cells. Abbreviations: CW, cell wall; Chl, chloroplast; $\mathrm{M}$, mitochondrion; PM, plasma membrane; $\operatorname{Bars}(\mathbf{A}, \mathbf{B}) 2 \mu \mathrm{m}$; (C-F) $0.5 \mu \mathrm{m}$.

$0.5,1.0$, and $1.5 \%$, respectively, implying that the inhibition of Fv/Fm was caused by the supernatant. Overall, the $1.5 \%$ treatment group showed a lower Fv/Fm value compared with the other treatments and the control $(p<0.01)$. The rETR, which was used to evaluate the photosynthetic capacity, showed a similar results with $\mathrm{Fv} / \mathrm{Fm}$ (Figures $\mathbf{8 B}, \mathrm{C}$ ). Figure $\mathbf{8 B}$ shows that rETR values decreased significantly $(p<0.01)$ at the 1.0 and $1.5 \%$ concentrations compared with the control during the first $4 \mathrm{~h}$ of exposure. Within the $24 \mathrm{~h}$ treatment, the rETR values in the 1.0 and $1.5 \%$ treatment groups decreased obviously $(p<0.01)$ compared with the $4 \mathrm{~h}$ treatment groups (Figure 8C). However, the rETR values of the $0.5 \%$ treatment group were slightly lower than those of the control group after treatment for 4 and $24 \mathrm{~h}$ (Figures 8B,C).

\section{EXPRESSION OF PHOTOSYNTHESIS-RELATED GENES AND RESPIRATION-RELATED GENES}

Figure 9 shows the effects of the BS02 supernatant on the relative transcript abundances of photosynthesis- and respiration-related

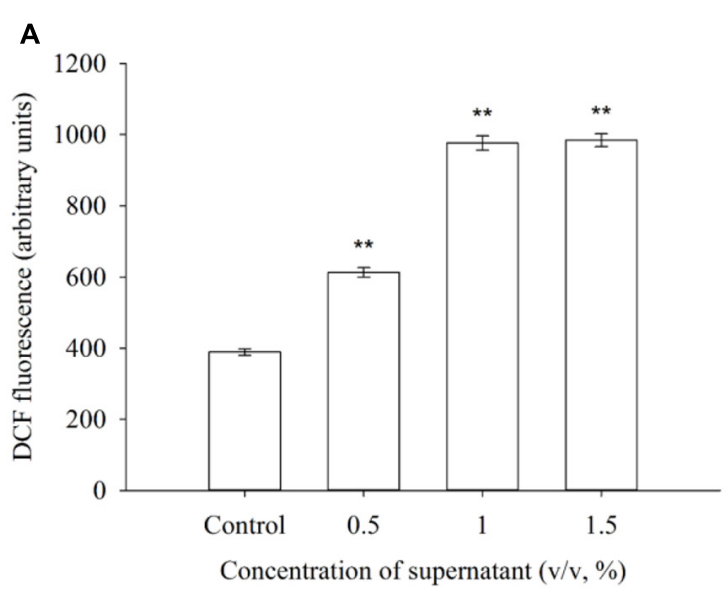

B

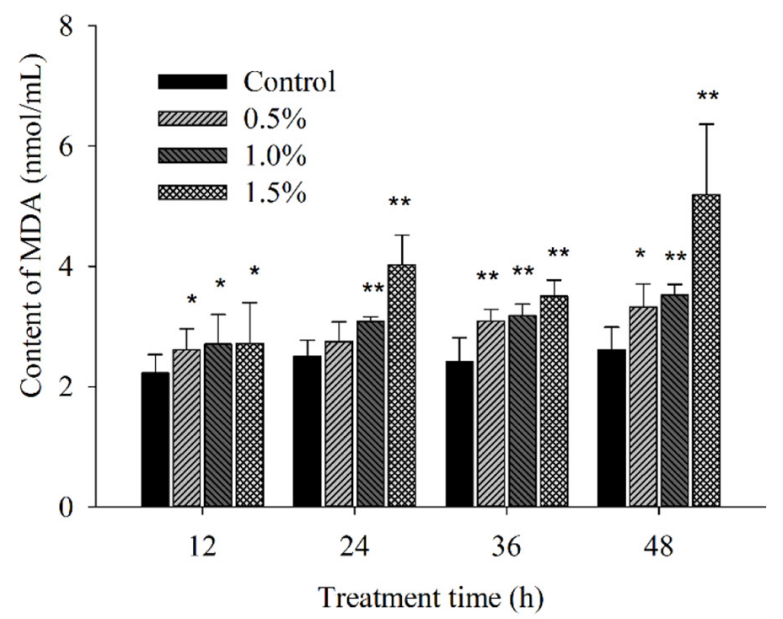

FIGURE 5 | Effects of BS02 supernatant on the ROS (A) and MDA (B) contents of $\boldsymbol{A}$. tamarense. All error bars indicate SE of the three replicates. ${ }^{*}$ represents a statistically significant difference of $p<0.05$ when compared to the control, ${ }^{*}$ represents a statistically significant difference of $p<0.01$.

genes after 4 and $24 \mathrm{~h}$ of exposure. To identify whether $p s b \mathrm{~A}$ responded to the BS02 supernatant, its expression was analyzed using qRT-PCR in cells that had been treated with BS02 supernatant for 4 and $24 \mathrm{~h}$. psbA transcript abundance was significantly affected by exposure to the BS02 supernatant (Figure 9A). Within $24 \mathrm{~h}$ of exposure, $p s b \mathrm{~A}$ gene expression in all treatment groups was significantly inhibited $(p<0.01)$ compared to the control, and the abundance of its transcript was $0.54,0.42$, and 0.26 times that of the control at the $0.5,1.0$, and $1.5 \%$ concentrations, respectively. However, transcription was stimulated during the initial exposure stage $(4 \mathrm{~h})$ in the $0.5 \%(p<0.01)$ group compared to the control. The relative expression of $p s b \mathrm{~A}$ was 1.18 times that of the control at the $0.5 \%$ concentration after $4 \mathrm{~h}$ of exposure.

The transcription of $p s b \mathrm{D}$ exhibited a somewhat different response to the BS02 supernatant compared with $p s b \mathrm{~A}$ (Figure 9B). Within $4 \mathrm{~h}$ of exposure to the $0.5 \%$ concentration, the transcription of $p s b \mathrm{D}$ decreased to 0.86 times that of 


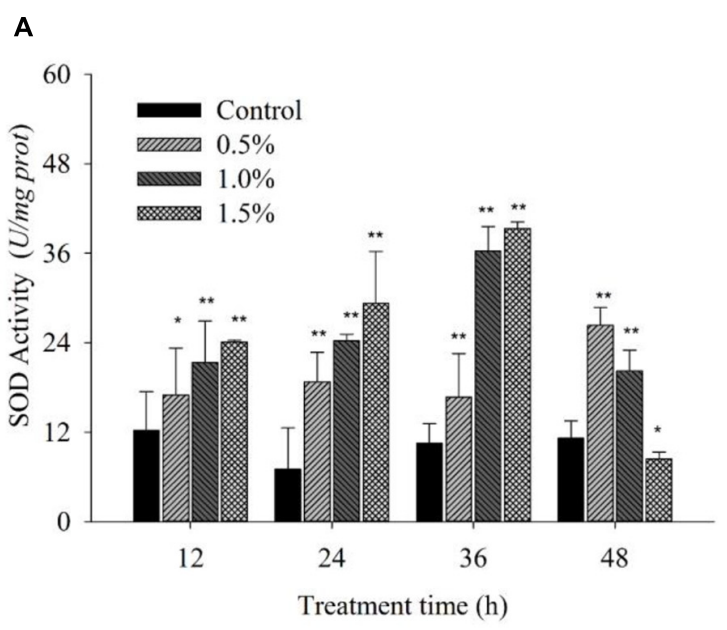

B

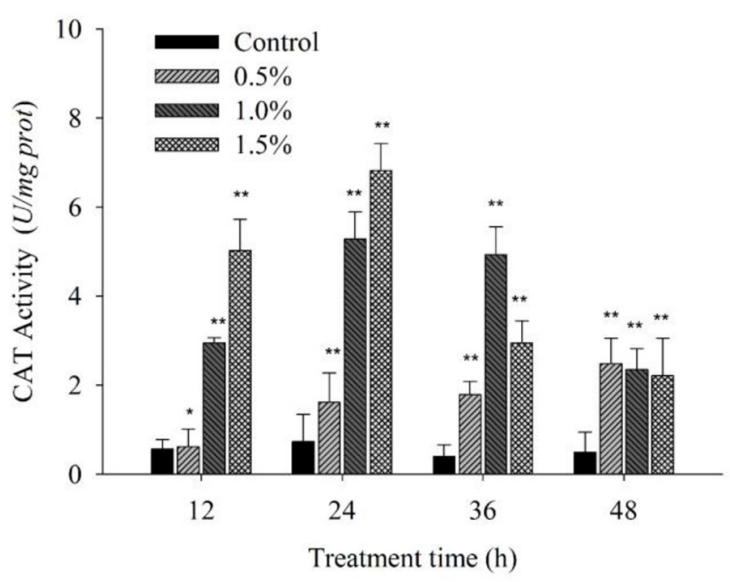

FIGURE 6 | Effects of BS02 supernatant on the SOD (A) and CAT (B) contents of $\boldsymbol{A}$. tamarense. All error bars indicate SE of the three replicates. ${ }^{*}$ represents a statistically significant difference of $p<0.05$ when compared to the control, **represents a statistically significant difference of $p<0.01$.

the control. However, this gene was up-regulated at all concentrations compared with the control after $24 \mathrm{~h}$ of exposure, and its expression levels were $2.58(p<0.01), 3.27(p<0.01)$, and 5.72 times $(p<0.01)$ those of the control in the $0.5,1.0$, and $1.5 \%$ treatment groups, respectively. Thus, $p s b \mathrm{D}$ transcription was increased at the higher treatment concentrations, especially the $1.5 \%$ concentration.

The transcription of $c o b$ was inhibited by the supernatant at concentrations of 1.0 and $1.5 \%$ after $4 \mathrm{~h}$ of exposure (Figure 9C). Within $24 \mathrm{~h}$ of exposure, the relative expression levels of $c o b$ were $0.88(p<0.05), 0.45(p<0.01)$, and 0.25 times $(p<0.01)$ those of the control at the $0.5,1.0$, and $1.5 \%$ concentrations, respectively. The abundance of the cox transcript was significantly inhibited by the BS02 supernatant (Figure 9D). Within $4 \mathrm{~h}$ of exposure, cox transcription was inhibited by $0.91-(p<0.01), 0.53-(p<0.01)$, and 0.33 -fold $(p<0.01)$ compared with the control in the 0.5 , 1.0 , and $1.5 \%$ treatment groups, respectively. The relative expression levels of cox were $0.26(p<0.01), 0.12(p<0.01)$, and 0.10

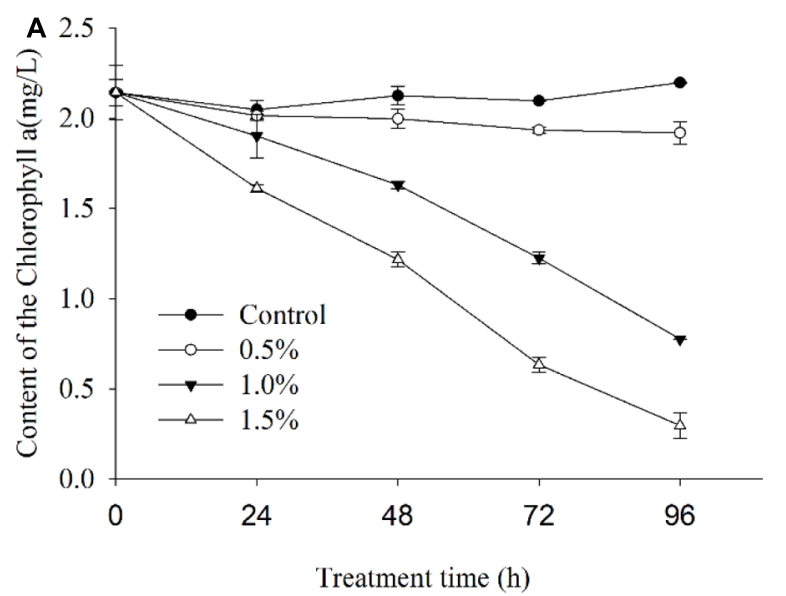

B

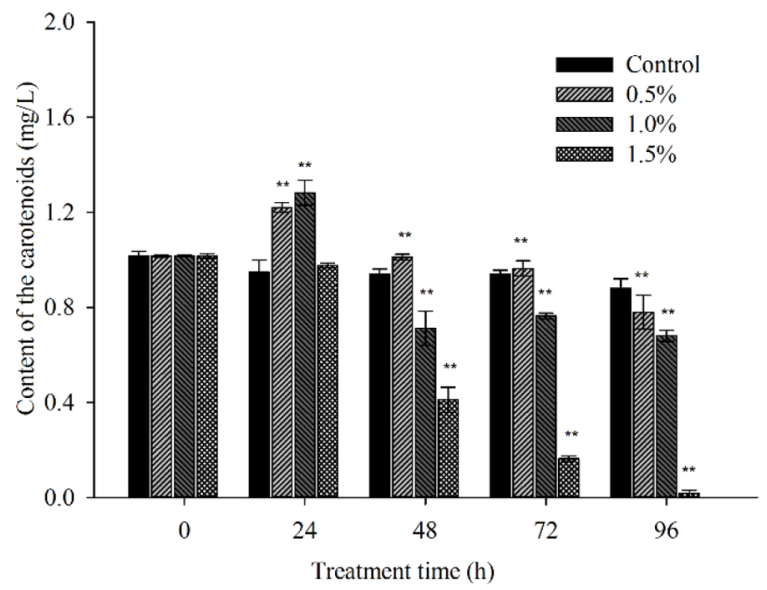

FIGURE 7 | Inhibitory effects of BS02 supernatant on chlorophyll a (A) and carotenoid (B) content in A. tamarense. All error bars indicate SE of the three replicates. ${ }^{* *}$ represents a statistically significant difference of $p<0.01$ when compared to the control.

times $(p<0.01)$ those of the control at the $0.5,1.0$, and $1.5 \%$ concentrations after $24 \mathrm{~h}$ of exposure, respectively.

\section{DISCUSSION}

\section{ALGICIDAL MODE OF BS02 SUPERNATANT AND LYSIS PROCESS OF}

\section{A. tamarense}

Blooms of $A$. tamarense species are associated with the largest number of paralytic shellfish poisoning cases around the world. There is an urgent need to seek effective methods to control the development of these blooms and to explore the associated mechanism of algal lysis. To date, there are few reports on the effects of bacteria on A. tamarense. To further explore the mechanism of the effects of the BS02 supernatant on this dinoflagellate, morphological changes, ROS levels, lipid peroxidation products, enzymatic antioxidants, pigment contents, Fv/Fm, and gene expression were assessed.

Algicidal bacteria can directly or indirectly attack algal cells, the former requiring cell-to-cell contact (Mayali and Azam, 2004) and the latter depending on active compounds produced by the 

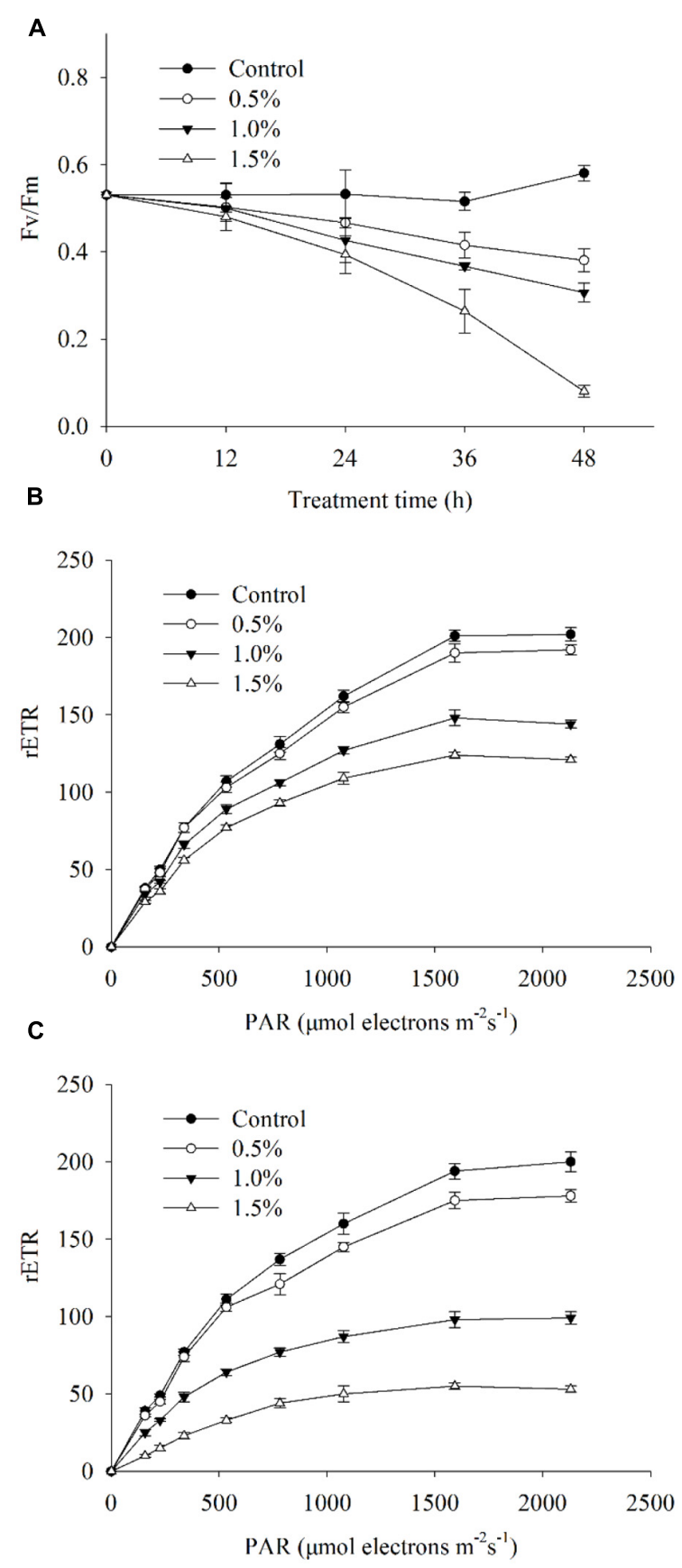

FIGURE 8 | Photosynthetic efficiency (Fv/Fm) (A), photosynthetic capacity (rETR) exposed for $4 \mathrm{~h}$ (B) and rETR exposed for $24 \mathrm{~h}$ (C) of A. tamarense cells treated with different concentrations of $\mathrm{BSO2}$ supernatant. All error bars indicate SE of the three replicates.

microorganism (Guan etal., 2014). The results of this study revealed that the strain BS02 lysed A. tamarense cells via active algicidal compounds in the cell-free supernatant (Figure 1). We found that the cell-free supernatant had high algicidal activity, similar to that of the bacterial cultures. However, negligible algicidal activity was shown for the washed bacterial cell treatment. These results implied that the algicidal mode of strain BS02 was indirect attack via the release of algicidal compounds rather than direct contact with the algal cells.

Scanning electron microscope and TEM were used in this study to visualize the lysis process and to reveal alterations in the ultrastructure of A. tamarense. We observed obvious morphological (Figure 3) and ultrastructure changes (Figure 4) of the $A$. tamarense cells induced by the BS02 supernatant compared to the normal cells. Obvious modifications appeared in the chloroplasts and mitochondria of the treated algal cells. Ultrastructural changes in chloroplasts can inhibit photosynthetic activity by decreasing electron transport, photon absorption and the reaction center of PS II in algae (Li etal., 2014b). TEM analysis also showed that the BS02 supernatant damaged the structure of the mitochondria, which disrupted normal respiration and induced algal death.

\section{EFFECT OF ROS LEVELS, MDA LEVEL AND ANTIOXIDATIVE ENZYME ACTIVITY}

Reactive oxygen species, including hydrogen peroxide, superoxide anion radicals and hydroxyl radicals, are unavoidable byproducts of oxygenic photosynthesis that cause oxidative damage and, ultimately, cell death (Alboresi et al., 2011; Yang etal., 2011). The inhibition of photosynthesis induces cells to produce numerous ROS, and excessive ROS cause lipid peroxidation and lead to severe cellular injury or death (Apel and Hirt, 2004; Bayr, 2005). The chloroplasts of algal cells, which exhibit intense electron flow, can produce ROS at high rates, causing oxidative damage to algal cells (Pérez-Pérez et al., 2012). Indirect damage by ROS includes the inhibition of photosynthesis, lipid peroxidation and photosynthetic oxidation (He and Häder, 2002). Our results demonstrated that the BS02 supernatant could significantly increase ROS levels in algal cells after $2 \mathrm{~h}$ of exposure (Figure 5A). At the 0.5 and $1.0 \%$ supernatant concentrations, ROS levels were significantly $(p<0.01)$ higher than those of the control, which indicated that the BS02 supernatant increased intracellular ROS significantly within a short period of time. At the highest treatment concentration, the ROS levels were markedly similar to those observed at the $1.0 \%$ concentration, indicating that excessive ROS were cleared by the antioxidative system of the algal cells. To characterize the lipid peroxidation level caused by ROS, the MDA level was measured.

Malondialdehyde is an indicator of lipid peroxidation and can reflect cellular oxidative damage, and Draper and Hadley (1990) have reported its use as an index of lipid peroxidation. In our study, the MDA level increased along with the BS02 supernatant concentration and duration of exposure. As shown in Figure 5B, we observed that the MDA level in all treatment groups increased compared to that in the control $(p<0.05)$ within $12 \mathrm{~h}$ of exposure. As the treatment time was prolonged, the MDA level was higher than that in the control group for each concentration. The $1.5 \%$ supernatant-treated group showed a higher level of MDA than the groups treated with lower concentrations, implying that the higher the concentration, the more serious the oxidative damage to algal cells. These results showed that increasing levels of ROS caused oxidative damage to the cellular membrane. The increases in the ROS and MDA levels following exposure to the BS02 supernatant suggested that the algae had suffered from oxidative stress and were 
A

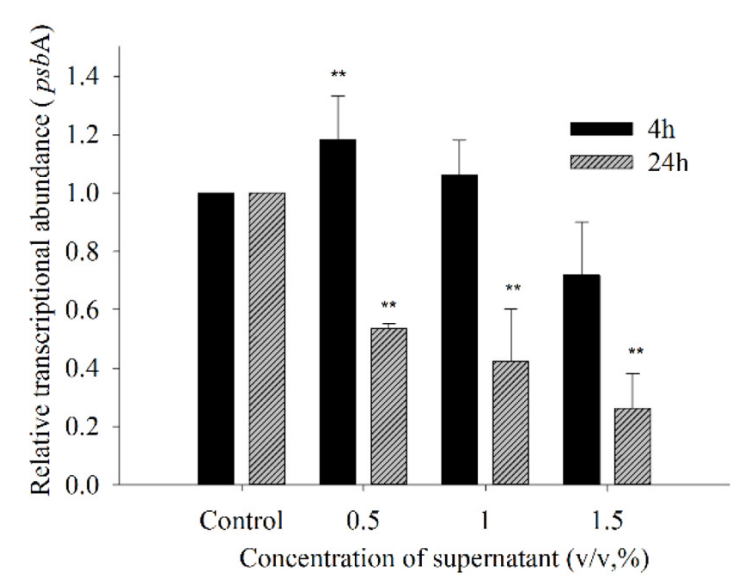

C

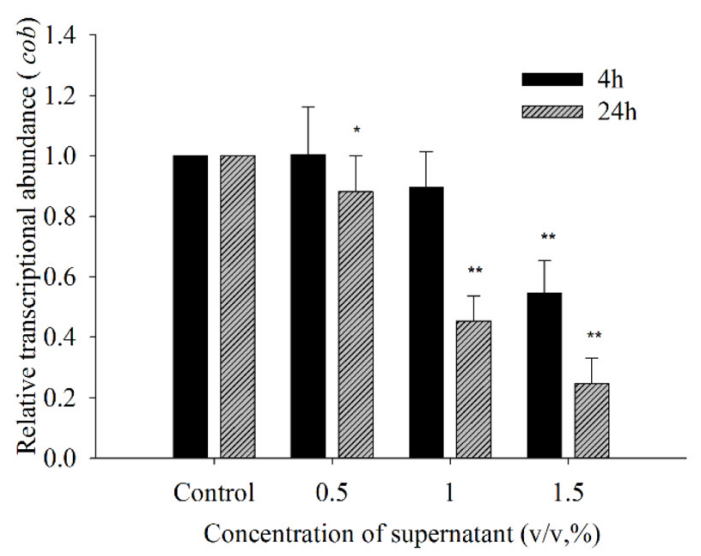

FIGURE 9 | Expression of psbA (A), psbD (B), cob (C), and cox (D) in A. tamarense exposed to different concentrations of BS02 supernatant supernatant for $\mathbf{4}$ and $\mathbf{2 4} \mathbf{h}$. All error bars indicate SE of the three
B

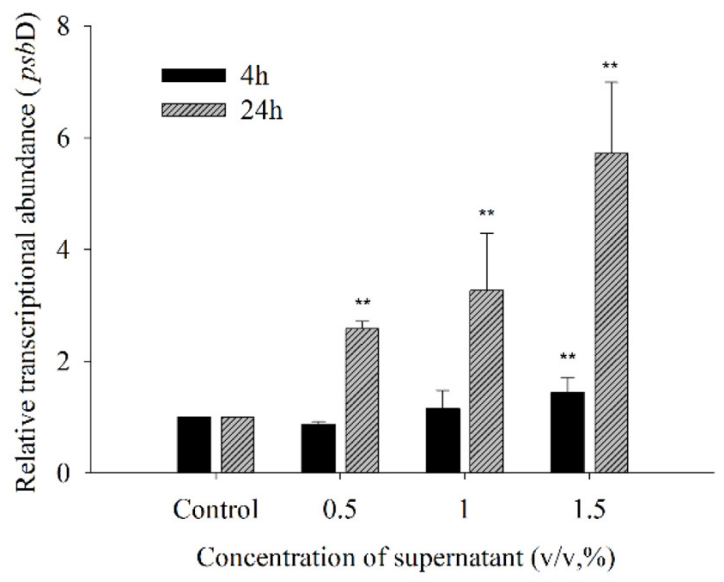

D

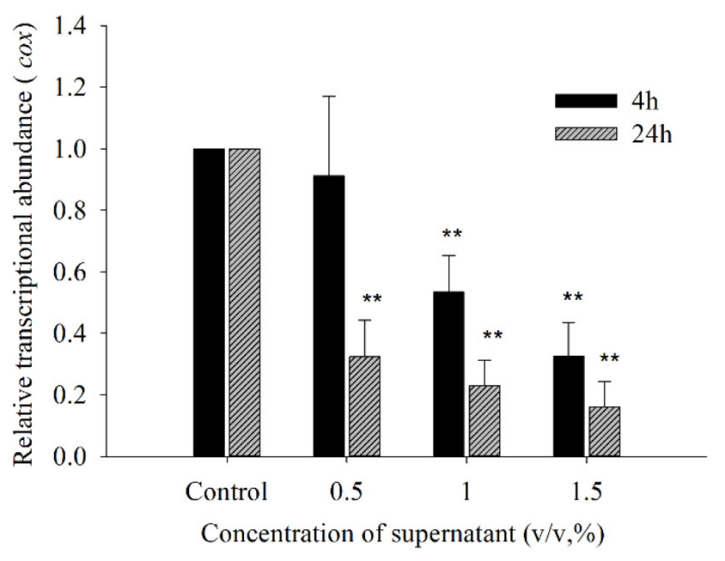

replicates. * represents a statistically significant difference of $p<0.05$ when compared to the control, ${ }^{*}$ represents a statistically significant difference of $p<0.01$. severely damaged. To avoid oxidative damage and scavenge ROS, algal cells possess a cellular defense system involving antioxidant enzymes, such as SOD and CAT (Zhang et al., 2011; Kwok et al., 2012).

Reactive oxygen species production and scavenging allow for the maintenance of homeostasis under normal metabolic conditions. However, when cells suffer from environmental stress, such as desiccation (Kumar et al., 2011), UV (Ryu et al., 2009) or high light (Solovchenko et al., 2011) or salinity (Luo and Liu, 2011), ROS metabolism becomes severely imbalanced, resulting in the accumulation of an abundance of ROS in cells, causing serious damage to the cells. Antioxidant enzymes play crucial roles in defense systems to protect cells against environmental stress. Our experiments showed that the algal cellular antioxidant enzymes (SOD and CAT) were triggered to differing degrees when cells were exposed to the BS02 supernatant (Figure 6). SOD and CAT activities were significantly $(p<0.01)$ enhanced compared to those of the control during the first $12 \mathrm{~h}$ of exposure to the 1.0 and $1.5 \%$ concentrations of the supernatant. These findings indicated that the SOD and CAT activities were activated within a short period of time. SOD activity increased gradually as the treatment time was prolonged up to $36 \mathrm{~h}$. However, it decreased significantly after $36 \mathrm{~h}$, implying that the BS02 supernatant stress in the algal cells was relieved. After $24 \mathrm{~h}$ of treatment, CAT activity began to decrease, similar to that of SOD. Although the activity of CAT decreased following the treatments with the 1.0 and $1.5 \%$ concentrations as the exposure time was prolonged, its activities at these concentrations were significantly $(p<0.01)$ higher compared with the control. These results might indicate that ROS levels were increased under BS02 supernatant stress and that the antioxidant enzymes (SOD and CAT) were activated to relieve ROS damage. In our study, the antioxidant enzymes responded actively to the BS02 supernatant effects and could relieve part of the damage caused by the ROS. However, excess ROS exceeded the functional capacities of the antioxidants and eventually led to oxidative damage.

\section{PIGMENT CONTENTS AND PHOTOSYNTHESIS EFFICIENCY ANALYSIS}

Chlorophyll $a$ plays a crucial role in algal photosynthesis and is the primary light-harvesting chromoprotein that transforms carbon dioxide into carbohydrates in algal cells (Chen, 2014). In 
our study, Chl a levels decreased significantly compared with the control after exposure to the 1.0 and $1.5 \%$ concentrations of supernatant for $24 \mathrm{~h}$. In addition, as the exposure time was prolonged and the concentration was increased, this reduction was even more obvious (Figure 7A). These findings indicated that the pigment structures were destroyed and that the impaired pigments were rapidly degraded. Carotenoids play important roles in controlling the efficiency of light harvesting and preventing the formation of highly reactive singlet oxygen and are thus fundamental components of the photosynthetic apparatus in algae (Santabarbara et al., 2013). The carotenoid level was significantly $(p<0.01)$ decreased following $48 \mathrm{~h}$ of exposure to the supernatant at concentrations of 1.0 and $1.5 \%$ (Figure 7B). These results indicated that carotenoid synthesis was diminished and that the ability of the algal cells to resist oxidative damage was also reduced.

The variable chlorophyll fluorescence illustrated the overall photosynthetic status of the algal cells, and Fv/Fm and rETR are two important parameters used to evaluate the photosynthesis efficiency and capacity (Schreiber et al., 1995). Our results revealed that the value of Fv/Fm significantly decreased $(p<0.01)$ after exposure to the BS02 supernatant (Figure 8A), suggesting that it inhibited photosynthetic efficiency. Similarly, the rETR was also significantly inhibited by BS02 supernatant, implying that the photosynthetic capacity of algal cells decreased after treatment with BS02 supernatant. These results indicated that the photosynthesis systems of algal cells were attacked by the BS02 supernatant. Considering these findings and those of the pigment assays, we suggest that the BS02 supernatant may act to destroy the photosynthetic system and accelerate the degradation of pigments, thus causing the dysfunctioning of this system.

\section{INVOLVEMENT OF PHOTOSYNTHESIS- AND RESPIRATION-RELATED GENES IN RESPONSE TO BS02 SUPERNATANT STRESS}

To reveal whether damage occurred to photosynthetic processes, the $p s b \mathrm{~A}$ and $p s b \mathrm{D}$ genes were assessed in our study. $p s b \mathrm{~A}$ and $p s b \mathrm{D}$ encode two core proteins, D1 and D2, which play pivotal roles in the photosynthetic reactions of PS II (Erickson et al., 1986). The BS02 supernatant greatly influenced the transcription of photosynthesis-and respiration-related genes. The expression of $p s b \mathrm{~A}$ increased significantly $(p<0.01)$ after $4 \mathrm{~h}$ of exposure to the $0.5 \%$ concentration of the supernatant in response to the reduction in chlorophyll. Within $24 \mathrm{~h}$ of exposure, $p s b \mathrm{~A}$ gene expression in all treatment groups was significantly inhibited $(p<0.01)$ compared to the control (Figure 9A), suggesting that the self-repair ability of the cells could not completely counteract the damage caused by the BS02 supernatant-induced stress. Within $24 \mathrm{~h}$ of exposure, $p s b \mathrm{D}$ gene expression in all treatment groups was significantly increased $(p<0.01)$ compared to the control (Figure 9B), implying that the degree of repair of PS II might have increased as the concentration of BS02 supernatant increased. Although $p s b \mathrm{D}$ gene expression in all treatment groups was significantly increased, the Fv/Fm values were still decreased. We speculated that the increased expression of $p s b \mathrm{D}$ might be associated with the repair of PS II (Ham et al., 2010). The higher supernatant concentration induced a higher self-repair ability, and the algicidal activity was relieved by a higher activity of self-repair. Zhang et al.
(2013) have reported that the transcriptional abundance of the $p s b \mathrm{D}$ gene is decreased in response to BS01 supernatant, while as the concentration of the BS01 supernatant increases, $p s b \mathrm{D}$ gene expression is increased. Takahashi and Badger (2011) have reported that sunlight damages PS II and causes photoinhibition, which is associated with a balance between the rate of photodamage and its repair. The photodamaged PS II is repaired through the synthesis of a new D1 protein (Murata et al., 2007); thus, the decreased expression of psbA may destroy the balance between the damage to PS II and its repair and the resulting inhibition of photosynthesis. The cob gene offers high sensitivity as a gene marker because it exists as multiple copies in many organisms (Zhang and Lin, 2005). cob is a cytochrome b-related gene, and $\operatorname{cox}$ is a cytochrome oxidase synthetic gene (Tobe et al., 2010). In our study, within $24 \mathrm{~h}$ of exposure, the expression levels of the $c o b$ and $c o x$ genes were significantly decreased $(p<0.05)$ in all treatment groups compared to the control (Figures 9C,D), implying that the inhibition of the respiratory system was caused by the BS02 supernatant. Yang et al. (2013) have also reported that the transcriptional abundance of the cob gene is significantly inhibited in response to the allelochemical hydroquinone. In summary, the transcription of photosynthesis- and respirationrelated genes is influenced by the BS02 supernatant to differing degrees.

\section{CONCLUSION}

The results of this study indicated that the algicidal bacterium strain BS02 has potential for use to control HABs. Our experiments demonstrated that changes occurred to the A.tamarense cells following exposure to the culture supernatant of the marine algicidal bacterium BS02. We found that the Vibrio sp. BS02 supernatant destroyed the morphological structure of $A$. tamarense cells, induced ROS production, inhibited Fv/Fm, and rETR, decreased pigment contents, and altered enzymatic antioxidant systems and the expression of photosynthesis- and respirationrelated genes. Our study demonstrated that this supernatant affected the expression of genes involved in the photosynthesis process and might have blocked the PS II electron transport chain, leading to the production of superfluous ROS. The excess ROS inhibited algal growth and ultimately induced algal cell death.

\section{ACKNOWLEDGMENTS}

This work was supported by the National Nature Science Foundation of China (41376119, 40930847), Public Science and Technology Research Funds Projects of Ocean (201305016) and Science and Technology Innovation Funds of Shenzhen (JCYJ20120615161239998). We also thank Prof. I. J. Hodgkiss of The University of Hong Kong for help with English.

\section{REFERENCES}

Alboresi, A., Dall'osto, L., Aprile, A., Carillo, P., Roncaglia, E., Cattivelli, L., et al. (2011). Reactive oxygen species and transcript analysis upon excess light treatment in wild-type Arabidopsis thaliana vs. a photosensitive mutant lacking zeaxanthin and lutein. BMC Plant Biol. 11:62. doi: 10.1186/1471-2229-11-62

Anderson, D. M. (1997a). Bloom dynamics of toxic Alexandrium species in the northeastern U.S. Limnol. Oceanogr. 42, 1009-1022. 
Anderson, D. M. (1997b). Turning back the harmful red tide. Nature 388, 513-514. doi: $10.1038 / 41415$

Anderson, D. M., Cembella, A. D., and Hallegraeff, G. M. (2012). Progress in understanding harmful algal blooms: paradigm shifts and new technologies for research, monitoring, and management. Annu. Rev. Mar. Sci. 4, 143-176. doi: 10.1146/annurev-marine-120308-081121

Apel, K., and Hirt, H. (2004). Reactive oxygen species: metabolism, oxidative stress, and signal transduction. Annu. Rev. Plant Biol. 55, 373-399. doi: 10.1146/annurev.arplant.55.031903.141701

Avery, S. (2011). Molecular targets of oxidative stress. Biochem. J. 434, 201-210. doi: 10.1042/BJ20101695

Bai, S. J., Huang, L. P., Su, J. Q., Tian, Y., and Zheng, T. L. (2011). Algicidal effects of a novel marine actinomycete on the toxic dinoflagellate Alexandrium tamarense. Curr. Microbiol. 62, 1774-1781. doi: 10.1007/s00284-0119927-z

Bayr, H. (2005). Reactive oxygen species. Crit. Care Med. 33, S498-S501. doi: 10.1097/01.CCM.0000186787.64500.12

Cai, W., Wang, H., Tian, Y., Chen, F., and Zheng, T. (2011). Influence of a bacteriophage on the population dynamics of toxic dinoflagellates by lysis of algicidal bacteria. Appl. Environ. Microbiol. 77, 7837-7840. doi: 10.1128/AEM. 05783-11

Chen, M. (2014). Chlorophyll modifications and their spectral extension in oxygenic photosynthesis. Annu. Rev. Biochem. 83, 317-340. doi: 10.1146/annurevbiochem-072711-162943

Chen, Z., Zhang, J., Lei, X., Zhang, B., Cai, G., Zhang, H., et al. (2014). Influence of plaque-forming bacterium, Rhodobacteraceae sp on the growth of Chlorella vulgaris. Bioresour. Technol. 169, 784-788. doi: 10.1016/j.biortech.2014. 07.021

Churro, C., Fernandes, A., Alverca, E., Sam-Bento, F., Paulino, S., Figueira, V., et al. (2010). Effects of tryptamine on growth, ultrastructure, and oxidative stress of cyanobacteria and microalgae cultures. Hydrobiologia 649, 195-206. doi: 10.1007/s10750-010-0245-4

Drábková, M., Admiraal, W., and Maršálek, B. (2007). Combined exposure to hydrogen peroxide and light selective effects on cyanobacteria, green algae, and diatoms. Environ. Sci. Technol. 41, 309-314. doi: 10.1021/es060746i

Draper, H., and Hadley, M. (1990). A review of recent studies on the metabolism of exogenous and endogenous malondialdehyde. Xenobiotica 20, 901-907. doi: 10.3109/00498259009046905

Erickson, J. M., Rahire, M., Malnoë, P., Girard-Bascou, J., Pierre, Y., Bennoun, P., et al. (1986). Lack of the D2 protein in a Chlamydomonas reinhardtii psbD mutant affects photosystem II stability and D1 expression. EMBO J. 5, 1745.

Evans, C., Malin, G., Mills, G. P., and Wilson, W. H. (2006). Viral infection of Emiliania huxleyi (prymnesiophyceae) leads to elevated production of reactive oxygen species. J. Phycol. 42, 1040-1047. doi: 10.1111/j.1529-8817.2006.00256.x

Franks, P., and Anderson, D. (1992). Alongshore transport of a toxic phytoplankton bloom in a buoyancy current: Alexandrium tamarense in the Gulf of Maine. Mar. Biol. 112, 153-164. doi: 10.1007/BF00349739

Gill, S. S., and Tuteja, N. (2010). Reactive oxygen species and antioxidant machinery in abiotic stress tolerance in crop plants. Plant Physiol. Bioch. 48, 909-930. doi: 10.1016/j.plaphy.2010.08.016

Guan, C., Guo, X., Cai, G., Zhang, H., Li, Y., Zheng, W., et al. (2014). Novel algicidal evidence of a bacterium Bacillus sp. LP-10 killing Phaeocystis globosa, a harmful algal bloom causing species. Biol. Control 76, 79-86. doi: 10.1016/j.biocontrol.2014.05.007

Guillard, R. R. L. (1975). “Culture of phytoplankton for feeding marine invertebrates culture of marine invertebrate animals," in Culture of Marine Invertebrate Animals, eds W. Smith and M. Chanley (New York: Plenum Press), 29-60. doi: 10.1007/9781-4615-8714-9_3

Ham, M.-H., Choi, J. H., Boghossian, A. A., Jeng, E. S., Graff, R. A., Heller, D. A., et al. (2010). Photoelectrochemical complexes for solar energy conversion that chemically and autonomously regenerate. Nat. chem. 2, 929-936. doi: 10.1038/nchem. 822

Hamilton, C. E., Gundel, P. E., Helander, M., and Saikkonen, K. (2012). Endophytic mediation of reactive oxygen species and antioxidant activity in plants: a review. Fungal Divers. 54, 1-10. doi: 10.1007/s13225-012-0158-9

He, Y., and Häder, D. P. (2002). Involvement of reactive oxygen species in the UVB damage to the cyanobacterium Anabaena sp. J. Photochem. Photobiol. B. 66, 73-80. doi: 10.1016/S1011-1344(01)00278-0
Hong, Y., Hu, H.-Y., Xie, X., Sakoda, A., Sagehashi, M., and Li, F.-M. (2009) Gramine-induced growth inhibition, oxidative damage and antioxidant responses in freshwater cyanobacterium Microcystis aeruginosa. Aquat. Toxicol. 91, 262-269. doi: 10.1016/j.aquatox.2008.11.014

Inskeep, W. P., and Bloom, P. R. (1985). Extinction coefficients of chlorophyll a and b in N, N-dimethylformamide and 80\% acetone. Plant Physiol. 77, 483-485. doi: 10.1104/pp.77.2.483

Jeong, H. J., Kim, J. S., Yoo, Y. D., Kim, S. T., Song, J. Y., Kim, T. H., et al. (2008). Control of the harmful alga Cochlodinium polykrikoides by the naked ciliate Strombidinopsis jeokjo in mesocosm enclosures. Harmful Algae 7, 368-377. doi: 10.1016/j.hal.2007.12.004

Jin, Q., and Dong, S. (2003). Comparative studies on the allelopathic effects of two different strains of Ulva pertusa on Heterosigma akashiwo and Alexandrium tamarense. J. Exp. Mar. Biol. Ecol. 293, 41-55. doi: 10.1016/S0022-0981(03)0 0214-4

Kaplan, F., Lewis, L. A., Herburger, K., and Holzinger, A. (2013). Osmotic stress in Arctic and Antarctic strains of the green alga Zygnema (Zygnematales, Streptophyta): effects on photosynthesis and ultrastructure. Micron 44, 317-330. doi: 10.1016/j.micron.2012.08.004

Kim, J.-D., Kim, J.-Y., Park, J.-K., and Lee, C.-G. (2009). Selective control of the Prorocentrum minimum harmful algal blooms by a novel algal-lytic bacterium Pseudoalteromonas haloplanktis AFMB-008041. Mar. Biotechnol. 11, 463-472. doi: 10.1007/s10126-008-9167-9

Kim, Y.-M., Wu, Y., Duong, T. U., Jung, S.-G., Kim, S. W., Cho, H., et al. (2012). Algicidal activity of thiazolidinedione derivatives against harmful algal blooming species. Mar. Biotechnol. 14, 312-322. doi: 10.1007/s10126-0119412-5

Kumar, M., Gupta, V., Trivedi, N., Kumari, P., Bijo, A., Reddy, C., et al. (2011). Desiccation induced oxidative stress and its biochemical responses in intertidal red alga Gracilaria corticata (Gracilariales, Rhodophyta). Environ. Exp. Bot. 72, 194-201. doi: 10.1016/j.envexpbot.2011.03.007

Kwok, C.-T., Van De Merwe, J. P., Chiu, J. M., and Wu, R. S. (2012). Antioxidant responses and lipid peroxidation in gills and hepatopancreas of the mussel Perna viridis upon exposure to the red-tide organism Chattonella marina and hydrogen peroxide. Harmful Algae 13, 40-46. doi: 10.1016/j.hal.2011.10.001

Lee, T., Nakano, K., and Matsumara, M. (2001). Ultrasonic irradiation for blue-green algae bloom control. Environ. Technol. 22, 383-390. doi: $10.1080 / 09593332208618270$

Li, D., Zhang, H., Fu, L., An, X., Zhang, B., Li, Y., et al. (2014a). A novel algicide: evidence of the effect of a fatty acid compound from the marine bacterium, Vibrio sp. Bs02 on the harmful dinoflagellate, Alexandrium tamarense. PLoS ONE 9:e91201. doi: 10.1371/journal.pone.0091201

Li, Y., Zhu, H., Guan, C., Zhang, H., Guo, J., Chen, Z., et al. (2014b). Towards molecular, physiological, and biochemical understanding of photosynthetic inhibition and oxidative stress in the toxic Alexandrium tamarense induced by a marine bacterium. Appl. Microbiol. Biotechnol. 98, 4637-4652. doi: $10.1007 /$ s00253-014-5578-x

Livak, K. J., and Schmittgen, T. D. (2001). Analysis of relative gene expression data using real-time quantitative PCR and the $2-\Delta \Delta$ ct method. Methods 25, 402-408. doi: 10.1006/meth.2001.1262

Luo, M. B., and Liu, F. (2011). Salinity-induced oxidative stress and regulation of antioxidant defense system in the marine macroalga Ulva prolifera. J. Exp. Mar. Biol. Ecol. 409, 223-228. doi: 10.1016/j.jembe.2011. 08.023

Marder, J., Chapman, D., Telfer, A., Nixon, P., and Barber, J. (1987). Identification of psbA and psbD gene products, D1 and D2, as reaction centre proteins of photosystem 2. Plant Mol. Biol. 9, 325-333. doi: 10.1007/ BF00014907

Mayali, X., and Azam, F. (2004). Algicidal bacteria in the sea and their impact on algal blooms. J. Eukaryot. Microbiol. 51, 139-144. doi: 10.1111/j.15507408.2004.tb00538.x

Murata, N., Takahashi, S., Nishiyama, Y., and Allakhverdiev, S. I. (2007). Photoinhibition of photosystem II under environmental stress. Biochim. Biophys. Acta 1767, 414-421. doi: 10.1016/j.bbabio.2006.11.019

Ni, L., Acharya, K., Hao, X., and Li, S. (2012). Isolation and identification of an anti-algal compound from Artemisia annua and mechanisms of inhibitory effect on algae. Chemosphere 88, 1051-1057. doi: 10.1016/j.chemosphere.2012. 05.009 
Paul, C., and Pohnert, G. (2013). Induction of protease release of the resistant diatom Chaetoceros didymus in response to lytic enzymes from an algicidal bacterium. PLoS ONE 8:e57577. doi: 10.1371/journal.pone.0057577

Peñuelas, J., Ribas-Carbo, M., and Giles, L. (1996). Effects of allelochemicals on plant respiration and oxygen isotope fractionation by the alternative oxidase. J. Chem. Ecol. 22, 801-805. doi: 10.1007/BF02033587

Pérez-Pérez, M. E., Lemaire, S. D., and Crespo, J. L. (2012). Reactive oxygen species and autophagy in plants and algae. Plant Physiol. 160, 156-164. doi: 10.1104/pp.112.199992

Pokrzywinski, K. L., Place, A. R., Warner, M. E., and Coyne, K. J. (2012). Investigation of the algicidal exudate produced by Shewanella sp. IRI-160 and its effect on dinoflagellates. Harmful Algae 19, 23-29. doi: 10.1016/j.hal.2012. 05.002

Qian, H., Li, J., Pan, X., Jiang, H., Sun, L., and Fu, Z. (2010). Photoperiod and temperature influence cadmium's effects on photosynthesis-related gene transcription in Chlorella vulgaris. Ecotoxicol. Environ. Saf. 73, 1202-1206. doi 10.1016/j.ecoenv.2010.07.006

Rijstenbil, J. (2002). Assessment of oxidative stress in the planktonic diatom Thalassiosira pseudonana in response to UVA and UVB radiation. J. Plankton Res. 24 1277-1288. doi: 10.1093/plankt/24.12.1277

Rosenwasser, S., Van Creveld, S. G., Schatz, D., Malitsky, S., Tzfadia, O., Aharoni, A., et al. (2014). Mapping the diatom redox-sensitive proteome provides insight into response to nitrogen stress in the marine environment. Proc. Natl. Acad. Sci. U.S.A. 111, 2740-2745. doi: 10.1073/pnas.1319773111

Ryu, B., Qian, Z.-J., Kim, M.-M., Nam, K. W., and Kim, S.-K. (2009). Antiphotoaging activity and inhibition of matrix metalloproteinase (MMP) by marine red alga, Corallina pilulifera methanol extract. Radiat. Phys. Chem. 78, 98-105. doi: 10.1016/j.radphyschem.2008.09.001

Santabarbara, S., Casazza, A. P., Ali, K., Economou, C. K., Wannathong, T., Zito, F., et al. (2013). The requirement for carotenoids in the assembly and function of the photosynthetic complexes in Chlamydomonas reinhardtii. Plant Physiol. 161, 535-546. doi: 10.1104/pp.112.205260

Schreiber, U., Bilger, W., and Neubauer, C. (1995). “Chlorophyll fluorescence as a nonintrusive indicator for rapid assessment of in vivo photosynthesis," in Ecophys iology of Photosynthesis, eds E.-D. Schulze and M. M. Caldwell (Berlin: Springer), 49-70.

Sengco, M. R., and Anderson, D. M. (2004). Controlling harmful algal blooms through clay flocculation. J. Eukaryot. Microbiol. 51, 169-172. doi: 10.1111/j.1550-7408.2004.tb00541.x

Sheik, A. R., Brussaard, C. P., Lavik, G., Lam, P., Musat, N., Krupke, A., et al. (2013). Responses of the coastal bacterial community to viral infection of the algae Phaeocystis globosa. ISME J. 8, 169-172. doi: 10.1038/ismej. 2013.135

Siswanto, E., Ishizaka, J., Tripathy, S. C., and Miyamura, K. (2013). Detection of harmful algal blooms of Karenia mikimotoi using MODIS measurements: a case study of Seto-Inland Sea, Japan. Remote Sens. Environ. 129, 185-196. doi: 10.1016/j.rse.2012.11.003

Solovchenko, A., Chivkunova, O., and Maslova, I. (2011). Pigment composition optical properties, and resistance to photodamage of the microalga Haematococcus pluvialis cultivated under high light. Russ. J. Plant Physl. 58, 9-17. doi: 10.1134/S1021443710061056

Suikkanen, S., Fistarol, G. O., and Granéli, E. (2004). Allelopathic effects of the Baltic cyanobacteria Nodularia spumdigena, Aphanizomenon flos-aquae and Anabaena lemmermannii on algal monocultures. J. Exp. Mar. Biol. Ecol. 308, 85-101. doi: 10.1016/j.jembe.2004.02.012

Sun, X.-X., Han, K.-N., Choi, J.-K., and Kim, E.-K. (2004). Screening of surfactants for harmful algal blooms mitigation. Mar. Pollut. Bull. 48, 937-945. doi 10.1016/j.marpolbul.2003.11.021

Takahashi, S., and Badger, M. R. (2011). Photoprotection in plants: a new light on photosystem II damage. Trends Plant Sci. 16, 53-60. doi: 10.1016/j.tplants.2010.10.001

Tang, Y., Zhang, H., Liu, X., Cai, D., Feng, H., Miao, C., et al. (2011). Flocculation of harmful algal blooms by modified attapulgite and its safety evaluation. Water Res. 45, 2855-2862. doi: 10.1016/j.watres.2011.03.003

Thamatrakoln, K., Korenovska, O., Niheu, A. K., and Bidle, K. D. (2012). Wholegenome expression analysis reveals a role for death-related genes in stress acclimation of the diatom Thalassiosira pseudonana. Environ. Microbiol. 14, 67-81. doi: 10.1111/j.1462-2920.2011.02468.x
Thyssen, M., Grégori, G. J., Grisoni, J.-M., Pedrotti, M. L., Mousseau, L., Artigas L. F., et al. (2014). Onset of the spring bloom in the northwestern Mediterranean Sea: influence of environmental pulse events on the in situ hourly-scale dynamics of the phytoplankton community structure. Front. Microbiol. 5:387. doi: $10.3389 /$ fmicb. 2014.00387

Tobe, S. S., Kitchener, A. C., and Linacre, A. M. (2010). Reconstructing mammalian phylogenies: a detailed comparison of the cytochrome b and cytochrome oxidase subunit I mitochondrial genes. PLoS ONE 5:e14156. doi: 10.1371/journal.pone.0014156

Vardi, A., Eisenstadt, D., Murik, O., Berman-Frank, I., Zohary, T., Levine, A., et al. (2007). Synchronization of cell death in a dinoflagellate population is mediated by an excreted thiol protease. Environ. Microbiol. 9, 360-369. doi: 10.1111/j.14622920.2006.01146.x

Vardi, A., Schatz, D., Beeri, K., Motro, U., Sukenik, A., Levine, A., et al. (2002). Dinoflagellate-cyanobacterium communication may determine the composition of phytoplankton assemblage in a mesotrophic lake. Curr. Biol. 12, 1767-1772. doi: 10.1016/S0960-9822(02)01217-4

Yang, C.-Y., Liu, S.-J., Zhou, S.-W., Wu, H.-F., Yu, J.-B., and Xia, C.-H. (2011). Allelochemical ethyl 2-methyl acetoacetate (EMA) induces oxidative damage and antioxidant responses in Phaeodactylum tricornutum. Pestic. Biochem. Physiol. 100, 93-103. doi: 10.1016/j.pestbp.2011.02.014

Yang, C., Zhou, J., Liu, S., Fan, P., Wang, W., and Xia, C. (2013). Allelochemical induces growth and photosynthesis inhibition, oxidative damage in marine diatom Phaeodactylum tricornutum. J. Exp. Mar. Biol. Ecol. 444, 16-23. doi: 10.1016/j.jembe.2013.03.005

Yin, L., Huang, J., Huang, W., Li, D., Wang, G., and Liu, Y. (2005). Microcystin-RR-induced accumulation of reactive oxygen species and alteration of antioxidant systems in tobacco BY-2 cells. Toxicon 46, 507-512. doi: 10.1016/j.toxicon.2005.06.015

Zhang, B., Cai, G., Wang, H., Li, D., Yang, X., An, X., et al. (2014). Streptomyces alboflavus RPS and its novel and high algicidal activity against harmful algal bloom species Phaeocystis globosa. PLoS ONE 9:e92907. doi: 10.1371/journal.pone.0092907

Zhang, H., An, X., Zhou, Y., Zhang, B., Zhang, S., Li, D., et al. (2013). Effect of oxidative stress induced by Brevibacterium sp. BSO1 on a HAB causing speciesAlexandrium tamarense. PLoS ONE 8:e63018. doi: 10.1371/journal.pone.00 63018

Zhang, H., and Lin, S. (2005). Development of a cob-18S rRNA gene realtime PCR assay for quantifying Pfiesteria shumwayae in the natural environment. Appl. Environ. Microbiol. 71, 7053-7063. doi: 10.1128/AEM.71.11.70537063.2005

Zhang, S., Zhang, B., Dai, W., and Zhang, X. (2011). Oxidative damage and antioxidant responses in Microcystis aeruginosa exposed to the allelochemical berberine isolated from golden thread. J. Plant Physiol. 168, 639-643. doi: 10.1016/j.jplph.2010.10.005

Zheng, X., Zhang, B., Zhang, J., Huang, L., Lin, J., Li, X., et al. (2013). A marine algicidal actinomycete and its active substance against the harmful algal bloom species Phaeocystis globosa. Appl. Microbiol. Biotechnol. 97, 9207-9215. doi: $10.1007 / \mathrm{s} 00253-012-4617-8$

Conflict of Interest Statement: The authors declare that the research was conducted in the absence of any commercial or financial relationships that could be construed as a potential conflict of interest.

Received: 05 November 2014; accepted: 05 January 2015; published online: 23 January 2015.

Citation: Lei X, Li D, Li Y, Chen Z, Chen Y, Cai G, Yang X, Zheng $W$ and Zheng $T$ (2015) Comprehensive insights into the response of Alexandrium tamarense to algicidal component secreted by a marine bacterium. Front. Microbiol. 6:7. doi: 10.3389/fmicb.2015.00007

This article was submitted to Microbiotechnology, Ecotoxicology and Bioremediation, a section of the journal Frontiers in Microbiology.

Copyright (C) 2015 Lei, Li, Li, Chen, Chen, Cai, Yang, Zheng and Zheng. This is an openaccess article distributed under the terms of the Creative Commons Attribution License (CC BY). The use, distribution or reproduction in other forums is permitted, provided the original author(s) or licensor are credited and that the original publication in this journal is cited, in accordance with accepted academic practice. No use, distribution or reproduction is permitted which does not comply with these terms. 